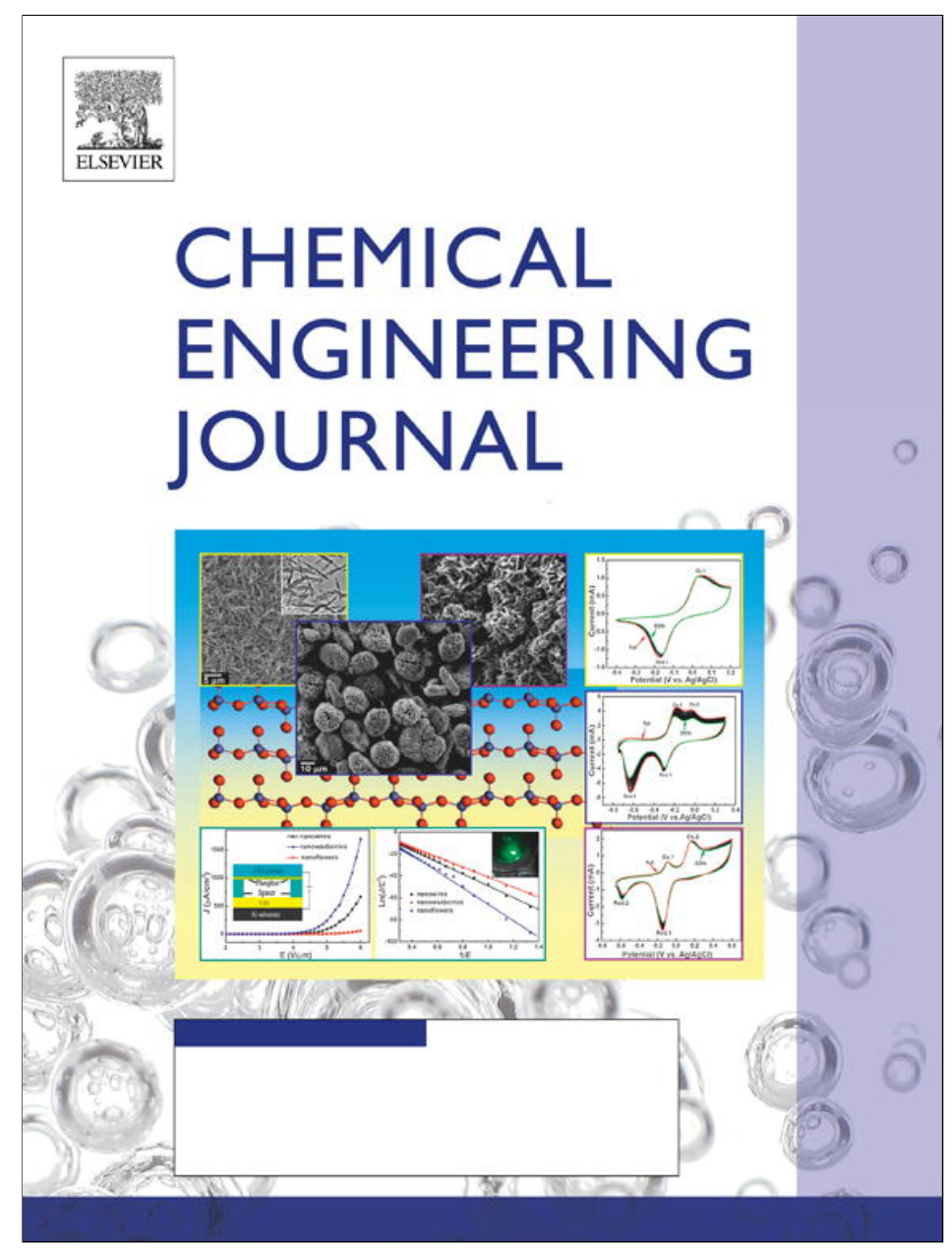

(This is a sample cover image for this issue. The actual cover is not yet available at this time.)

This article appeared in a journal published by Elsevier. The attached copy is furnished to the author for internal non-commercial research and education use, including for instruction at the authors institution and sharing with colleagues.

Other uses, including reproduction and distribution, or selling or licensing copies, or posting to personal, institutional or third party websites are prohibited.

In most cases authors are permitted to post their version of the article (e.g. in Word or Tex form) to their personal website or institutional repository. Authors requiring further information regarding Elsevier's archiving and manuscript policies are encouraged to visit: 


\title{
In situ biodiesel production from wet Chlorella vulgaris under subcritical condition
}

\author{
Yeshitila Asteraye Tsigie $^{\text {a }}$, Lien Huong Huynh ${ }^{\mathrm{b}}$, Suryadi Ismadji ${ }^{\mathrm{c}}$, Adam Mekonnen Engida ${ }^{\mathrm{a}}$, Yi-Hsu Ju ${ }^{\mathrm{a}, *}$ \\ ${ }^{a}$ Department of Chemical Engineering, National Taiwan University of Science and Technology, 43 Keelung Rd., Sec. 4, Taipei 106-07, Taiwan \\ ${ }^{\mathrm{b}}$ Department of Chemical Engineering, Can Tho University, Can Tho City, Viet Nam \\ c Chemical Engineering Department, Widya Mandala Surabaya Catholic University, Kalijudan 37, Surabaya 60114, Indonesia
}

\section{H I G H L I G H T S}

- The conventional biodiesel production process is not environmentally friendly.

- Biodiesel can be made directly from wet algal biomass and subcritical methanol.

- Stirring shortens the reaction time to achieve high conversion yield of FAMEs.

\section{A R T I C L E I N F O}

\section{Article history:}

Received 14 March 2012

Received in revised form 14 September 2012

Accepted 22 September 2012

Available online 11 October 2012

\section{Keywords:}

Biodiesel

FAME

Subcritical water

Chlorella vulgaris

\begin{abstract}
A B S T R A C T
The conventional base catalyzed biodiesel production process uses refined vegetable oil as feedstock oil and is not environmentally friendly. The supercritical methanol technology does not require the use of catalyst but it is energy intensive due to the high temperature and pressure required in the process. In this work, a process was developed for producing biodiesel directly from wet Chlorella vulgaris biomass (80\% moisture content) using subcritical water as catalyst. Under the following conditions: The ratio of wet biomass to methanol is $1 / 4(\mathrm{~g} / \mathrm{mL})$, the reaction temperature is $175^{\circ} \mathrm{C}$ and after $4 \mathrm{~h}$, the reaction product contained $89.71 \%$ fatty acid methyl esters (FAMEs). The yield is $0.29 \mathrm{~g}$ FAME per $\mathrm{g}$ dry biomass. This is considerably higher than the yield of $0.20 \mathrm{~g}$ FAME per g dry biomass obtained when the neutral lipid of $C$. vulgaris biomass was extracted and converted into FAME.
\end{abstract}

(C) 2012 Elsevier B.V. All rights reserved.

\section{Introduction}

In order to satisfy the world's energy demand for fuel and decrease the dependence on fossil fuels, research has been directed towards finding renewable, clean and environmentally-friendly alternative energy sources. Biofuel, especially biodiesel, is one such source that is receiving special attention. Oleaginous microalgae are being considered as potential feedstock for biodiesel production. Their rapid growth rate and high intracellular lipid content $[1,2]$ make them a potential candidate for feedstock. Chlorella strains have been considered as promising candidates for commercial lipid production due to their fast growth and easy cultivation. In addition Chlorella strains are not contaminated by other strains of microalgae when cultivated in open ponds [3].

Although high biomass productivity, rapid lipid accumulation and ability to survive in saline water make microalgae a promising feedstock for industrial-scale biodiesel production. The high cost of producing microalgae biomass and conventional biodiesel production processes make biodiesel production from microalgae biomass

\footnotetext{
* Corresponding author. Tel.: +886 2 27376612; fax: +886227376644

E-mail address: yhju@mail.ntust.edu.tw (Y.-H. Ju).
}

uneconomical [4]. The conventional method used for biodiesel preparation from microalgae is to first extract lipids. The lipids are then converted into fatty acid alkyl esters. The extraction efficiency depends on factors such as microalgae species, method of cell wall disruption and solvent used for extraction [5-8]. Cell disruption prior to extraction can increase the amount of extractable oil. The most commonly used physicochemical techniques for microalgal cell disruption include grinding followed by ultrasonication, microwave treatment, autoclaving, bead-beating and sonication $[9,10]$. However, the oil extraction step is considered uneconomical. Attention is now being focused on direct or in situ production of biodiesel from microalgae biomass.

The conventional production of biodiesel uses refined oil (with free fatty acid (FFA) content less than $0.5 \%$ ). This refined oil reacts with methanol and is catalyzed by alkali. The biodiesel production from microalgae uses alkali as a catalyst. This would not be suitable due to the high FFA content of microalgae lipids. The high FFA concentration leads to soap formation and difficulties in biodiesel purification [11].

Most studies on biodiesel production from microalgae were based on dry algal biomass. It was necessary to remove the water after harvesting biomass. Drying the biomass is energy intensive 
and efforts are currently devoted to develop process for producing biodiesel directly from wet algal biomass. A two-step process to produce biodiesel from wet biomass of $C$. vulgaris was proposed by Levine et al. [12]. In the first step, wet algal biomass (80\% moisture) was hydrolyzed in subcritical water to release intracellular lipids. In the second step, the fatty acid-rich wet biomass was reacted with ethanol under supercritical condition to produce biodiesel. They reported a maximum fatty acid ethyl ester yield of $66 \%(w / w)$. During acid catalyzed in situ production of biodiesel from biomass, inhibition occurred when the biomass water content was greater than $115 \%$ [13].

One step in situ biodiesel production eliminates unnecessary and complex steps such as oil extraction. Velasquez-Orta et al. [14] reported that in situ alkali catalyzed transesterification of dry algal biomass can achieve high conversion (77.6\%) in less time than that when using an acid catalyst. Xu and Mi [15] showed that addition of co-solvents such as mixture of toluene and methanol $(2: 1, v / v)$ resulted in the highest efficiency. They achieved a $86 \%$ yield from the in situ transesterification. It was found that in the in situ transesterification of the wet algae biomass, neutral lipids such as triacylglycerols (TAGs), free fatty acids (FFAs) and phospholipids all contributed to the formation of fatty acid methyl esters (FAMEs) [16].

It is still a challenge to minimize the cost in biodiesel production related to the use of acid, base and biological catalysts. The catalyst can be eliminated if production is done under supercritical conditions. The supercritical methanol method is simpler, more environmentally friendly and can reach high conversion (>95\%) in a very short time. The presence of high contents of FFAs and water has no effect on the efficiency of this method [17-20]. In this reaction, a single homogenous phase is formed between methanol and oil. This accelerates the reaction by eliminating mass transfer resistance between phases. Pretreatment of feedstock is not required [21]. A high alcohol to oil molar ratio (usually $>40: 1$ ), a high temperature $\left(300-350^{\circ} \mathrm{C}\right.$ ) and a high pressure (20-50 MPa) makes this process energy intensive $[22,23]$.

Reaction involving subcritical water (SCW) is considered as environmentally friendly. SCW can be used for extraction, hydrolysis, and wet oxidation of organic compounds. SCW is water at temperatures between 100 and $374{ }^{\circ} \mathrm{C}$ under high pressure to maintain it in liquid state. The dielectric constant is the most important factor when using water as solvent for extraction. It decreases from 80 at room temperature to 27 at $250{ }^{\circ} \mathrm{C}$ [24-26]. In a previous work, it was reported that SCW pretreatment of the biomass of the oleaginous yeast Yarrowia lipolytica Po1 g can increase its extractable neutral lipids two folds [27]. SCW can also act as an effective catalyst for hydrolysis or biodegradation reactions and to increase the extractable neutral lipids from activated sludge $[28,29]$. Base catalyzed methanolysis of soybean oil under a subcritical condition of $160{ }^{\circ} \mathrm{C}$ was reported by Yin et al. [30]. A 98\% yield of methyl esters can be obtained in $10 \mathrm{~min}$. Without using a catalyst, only a $6 \%$ yield of methyl ester was obtained at $260{ }^{\circ} \mathrm{C}$.

The present work was focused on investigating the in situ preparation of fatty acid methyl esters (FAMEs) from wet $C$. vulgaris biomass without the need of traditional acid or base catalyst. The effects of reaction time, amount of methanol and stirring on the FAME yield were systematically investigated.

\section{Materials and methods}

\subsection{Apparatus and chemicals}

Solvents and reagents used in the experiments are either gas chromatography (GC) or analytical reagent grade obtained from different suppliers. For GC analysis, all standards of fatty acids and FAMEs were purchased from Acros Organics (New Jersey, USA) and Sigma-Aldrich (St. Louis, MO 63103, USA), respectively. Qualitative filter paper (grade No. 2, $0.26 \mathrm{~mm}$ thickness, $80 \%$ collection efficiency and grade No. 5C) was obtained from Advantec (Tokyo, Japan). A 37 components FAME mixture was supplied by Sigma-Aldrich (Bellefonte, USA). GC-2010 gas chromatograph equipped with a flame ionization detector (Shimadzu, Japan) and a polar column Rtx-2330 composed of $10 \%$ cyanopropylphenyl$90 \%$ biscyanopropyl polysiloxane $(30 \mathrm{~m} \times 0.25 \mathrm{~mm}$, Restek, Bellefonte, PA) were used for analyzing FAMEs in the reaction product. For analysis of lipid contents and fatty acid profile, a gas chromatograph (GC-17A, Shimadzu, Japan) with a flame ionization detector and a DB5-HT capillary column $(30 \mathrm{~m} \times 0.32 \mathrm{~mm})$ were used. Magnetic stirring was provided by using a Corning PC 320 hot plate magnetic stirrer model PC-320 (Lowell, USA).

\subsection{Experimental setup}

All reactions were conducted in a stainless steel autoclave reactor. The reactor has a working volume of about $175 \mathrm{~mL}$. The reactor is $2 \mathrm{~cm}$ thick and can withstand an estimated maximum operation pressure of $20 \mathrm{MPa}$. Temperature and pressure in the reactor was monitored by a thermocouple and a pressure gauge, respectively. Nitrogen gas (99.9\% purity) was used to maintain pressure in the reactor required to keep water and methanol in liquid state. The experimental setup is shown in Fig. 1.

\subsection{Production of biodiesel from C. vulgaris biomass}

The objective of this study was to produce biodiesel from wet microalgae biomass. The biomass was cultivated according to Yeh et al. [31]. Typically, $5 \mathrm{~g}$ of wet $C$. vulgaris biomass (moisture content adjusted to $80 \%$ by adding $4 \mathrm{~mL}$ deionized water to $1 \mathrm{~g}$ dry biomass) and a pre-determined amount of methanol were put into the reactor. Temperature in the reactor was raised to $175^{\circ} \mathrm{C}$, with a corresponding vapor pressure of about 22 bar, based on results from our previous works $[27,28]$. After a pre-determined time, reaction was stopped by releasing vapor in the reactor to reduce the pressure to about 2 bar. The reactor was cooled to room temperature and its content was transferred to a separatory funnel. Hexane was then added and after shaking, the aqueous and organic phases were separated. After removing hexane in the organic phase, its composition was analyzed. Fig. 2 is the flowchart showing the producing of biodiesel from wet microalgae.

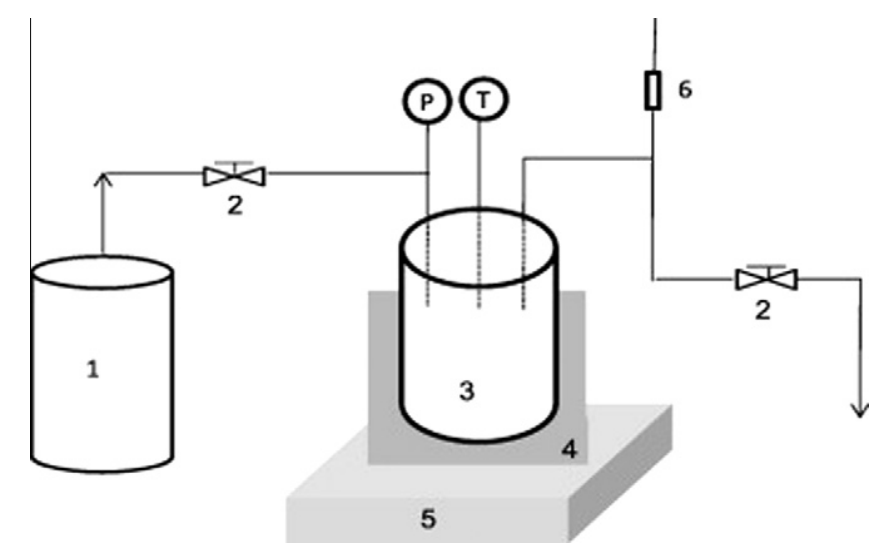

Fig. 1. Schematic diagram of reactor set-up. (1) Nitrogen cylinder. (2) Needle valve. (3) Reactor. (4) Electric heater. (5) Magnetic stirrer plate. (6) Safety valve. $(P)$ Pressure gauge. $(T)$ Thermocouple. 


\subsection{Analysis of reaction product}

FFA and acylglycerols (AGs) contents of the reaction products were analyzed by using a GC-17A gas chromatograph (Shimadzu, Japan) with a flame ionization detector, as described elsewhere [32]. Separations were carried out on a DB5-HT capillary column $(30 \mathrm{~m} \times 0.32 \mathrm{~mm}$; Agilent Technologies, USA). Temperatures of the injector and the detector were both set at $370^{\circ} \mathrm{C}$. Temperature of the column was started at $80^{\circ} \mathrm{C}$, then was increased to $365^{\circ} \mathrm{C}$ at a rate of $15^{\circ} \mathrm{C} / \mathrm{min}$ and maintained at $365^{\circ} \mathrm{C}$ for $10 \mathrm{~min}$. The total run time was $29 \mathrm{~min}$. The split ratio was $1: 50$ using nitrogen as the carrier gas with a linear velocity of $30 \mathrm{~cm} / \mathrm{s}$ at $80^{\circ} \mathrm{C}$. A $20 \mathrm{mg}$ sample was dissolved in $1 \mathrm{~mL}$ ethyl acetate, and $0.5 \mu \mathrm{L}$ sample was taken and injected into the GC. To identify the types of fatty acids in the products, $20 \mathrm{mg}$ of a standard of fatty acid was dissolved in $1 \mathrm{~mL}$ ethyl acetate and $0.5 \mu \mathrm{L}$ was injected into the GC.

\subsection{Determination of FAME profile}

Chromatographic analysis of FAME profile in the product was performed using a GC-2010 gas chromatograph (Shimadzu, Japan) equipped with a flame ionization detector. The column used was Rtx-2330 10\% cyanopropylphenyl-90\% biscyanopropyl polysiloxane column $30 \mathrm{~m} \times 0.25 \mathrm{~mm}$ i.d., (Restek, Bellefonte, PA). The operating conditions were as follows. The injector and detector temperatures were set at $250^{\circ} \mathrm{C}$. The column temperature was held at $150{ }^{\circ} \mathrm{C}$ for $2 \mathrm{~min}$, and then raised to $250^{\circ} \mathrm{C}$ at $5{ }^{\circ} \mathrm{C} / \mathrm{min}$ and held for $8 \mathrm{~min}$. Hydrogen flow, air flow and make up flow were set at $50.0 \mathrm{~mL} / \mathrm{min}, 500.0 \mathrm{~mL} / \mathrm{min}$ and $30 \mathrm{~mL} / \mathrm{min}$, respectively. The linear velocity and purge flow were $8.0 \mathrm{~cm} / \mathrm{s}$ and $3.0 \mathrm{~mL} / \mathrm{min}$, respectively. Individual FAME was identified by comparing its retention time with the retention times of a 37-component FAME mix (Sigma-Aldrich, Bellefonte, USA). Total biodiesel yield was calculated by using the equation:

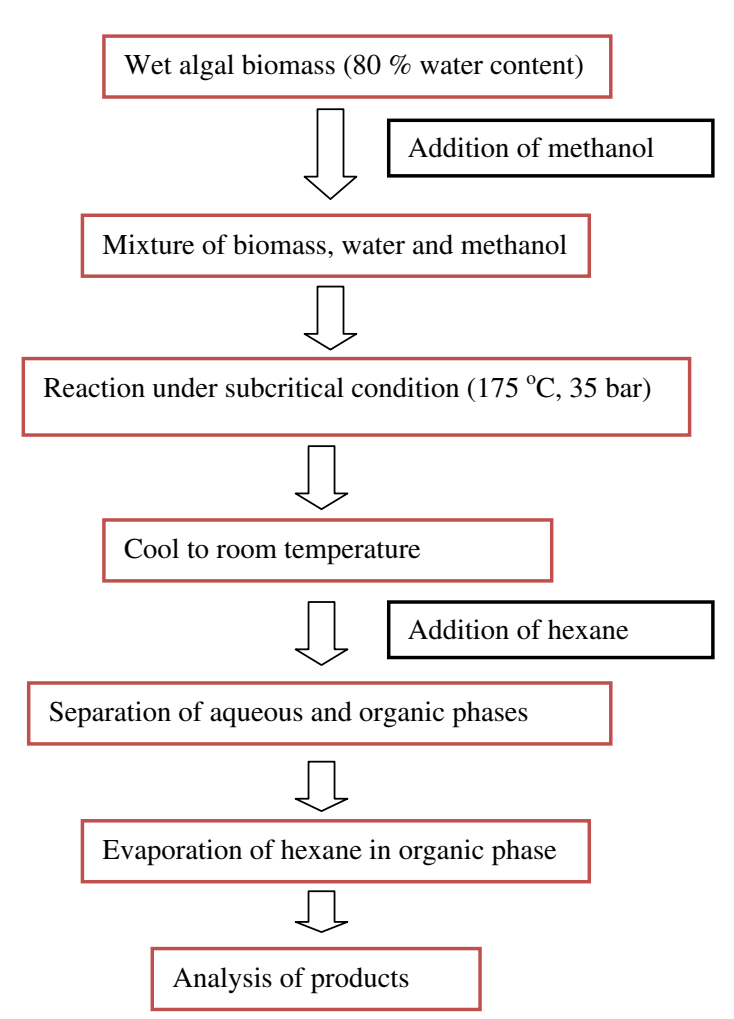

Fig. 2. Flow chart for the preparation of biodiesel from wet microalgae.
Total FAMEs yield $(\%, \mathrm{w} / \mathrm{w})=\frac{\text { Total weight of FAMEs }(\mathrm{g})}{\text { Dry biomass }(\mathrm{g})} \times 100 \%$

FAME conversion (\%, peak area) was calculated based on peak area of the GC chromatogram of the reaction product.

$$
\begin{aligned}
& \text { FAMEs conversion yield }(\% \text {, peak area }) \\
& =\frac{\text { Total peak area of FAMEs }}{\text { Total peak area of the products }} \times 100 \%
\end{aligned}
$$

\section{Results and discussion}

\subsection{Effect of reaction time and stirring}

Variables such as reaction time, type and amount of alcohol, catalysts, temperature and method of preparation play important roles in determining biodiesel yield from different feedstocks [13]. Tsigie et al. [27] showed that after SCW pretreatment, the extractable lipid of Yarrowia lipolytica biomass increased two times. It has been suggested that SCW hydrolysis of vegetable oils is predominately a homogeneous reaction in the oil phase, consisting of three reversible stepwise reactions that convert triacylglycerol (TAG) into diacylglycerol (DAG), monoacylglycerol (MAG), and finally glycerol [33].

To study the effect of reaction time and stirring on FAMEs yield, the reaction mixture was allowed to react for a predetermined time $(0,2,4,6$ or $8 \mathrm{~h})$ with or without stirring. The results are shown in Fig. 3. A general trend was observed. An increase in reaction time has a positive effect on the amount of FAMEs that can be produced from the microalge biomass.

According to Ehimen et al. [13], during in situ acid catalyzed transesterification of Chlorella biomass, the FAME yield increased from $70 \%$ to $92 \%$ when reaction time was increased from 15 min to $1 \mathrm{~h}$. These results are better than the results of this study. The maximum FAME yields were obtained at $4 \mathrm{~h}(88.65 \%$, with stirring) and at $8 \mathrm{~h}$ (89.12\%, without stirring). An acid catalyzed in situ FAMEs synthesis from Chaetoceros gracilis biomass indicated that increasing time from $25 \mathrm{~min}$ to $2.5 \mathrm{~h}$ using $2.5 \mathrm{~mL}$ methanol per $100 \mathrm{mg}$ biomass, increased the yield of FAME from $7.4 \%$ to $22.6 \%$ [16]. A longer time ( $\geqslant 4 \mathrm{~h}$ ) is necessary for high FAME yield during in situ, uncatalyzed FAMEs synthesis from wet $C$. vulgaris. A longer time is necessary to break down cell wall, expose lipids in the cells

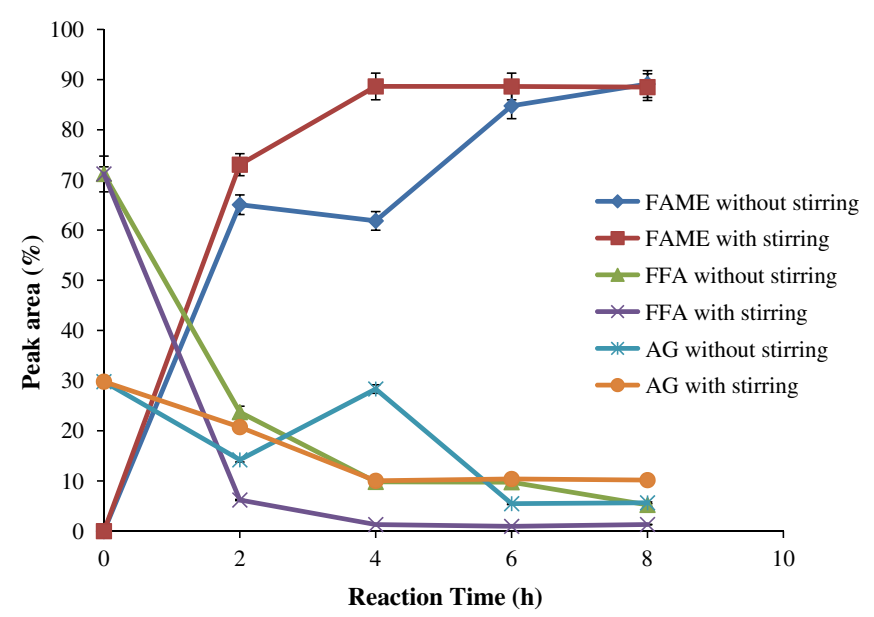

Fig. 3. Effect of reaction time and stirring on product composition. Reaction conditions: $5 \mathrm{~g}$ wet microalgae $\left(80 \%\right.$ moisture content), $30 \mathrm{~mL}$ methanol, $175^{\circ} \mathrm{C}$ and 22 bar. Data are average of at least two independent experiments. 
and react lipid with methanol under subcritical condition without using acid catalyst.

Stirring significantly increases the rate of biodiesel formation in the acid-catalyzed in situ production of biodiesel from microalgae lipids [13]. In our study, the effect of stirring on the in situ process was investigated and the results are shown in Fig. 3. During the first $2 \mathrm{~h}$ of reaction, no significant difference was observed in the FAME yields between reaction with and without stirring. The maximum achievable FAME yield at $2 \mathrm{~h}$ was $69.07 \%$ without stirring and $71.05 \%$ with stirring. A maximum FAME yield of $88.65 \%$ can be obtained in $4 \mathrm{~h}$ with stirring. It took $8 \mathrm{~h}$ to reach a maximum FAME content of $89.12 \%$ without stirring. The effect of stirring on FAME content is most pronounced at $4 \mathrm{~h}$. At $6 \mathrm{~h}$ and $8 \mathrm{~h}$, the differences in FAME contents between reactions with stirring and without stirring are insignificant.

The purpose of stirring was to prevent clumping and ensure that biomass was adequately exposed to methanol. When the in situ transesterification was conducted without stirring, the conversion of microalgae oil to FAME was significantly lower than that with stirring. This phenomenon was also observed in the in situ acid catalyzed transesterification of microalgal biomass [13]. Ma et al. [39] reported that stirring had a significant effect on the transesterification of beef tallow and methanol.

A catalyst free, two-step biodiesel production from wet C. vulgaris was developed by Levine et al. [15]. Without stirring the reaction mixture, they showed that hydrolysis of wet algal biomass by SCW at $250{ }^{\circ} \mathrm{C}$ followed by supercritical in situ transesterification with ethanol at $275^{\circ} \mathrm{C}$ for $2 \mathrm{~h}$ produces crude biodiesel of which $79 \%(w / w)$ is fatty acid ethyl esters [15]. Our work suggested a maximum FAME yield (88.65\%) through a simple one step SCW assisted reaction at $175^{\circ} \mathrm{C}$ with continuous stirring. Better results can be achieved with in situ transesterification of wet microalgae biomass with stirring at considerably lower temperature.

\subsection{Effect of methanol amount}

During in situ transesterification, alcohol acts both as solvent for extracting lipids from biomass and as the reactant for converting lipids to fatty acid esters [16]. In transesterification of lipids and alcohol, alcohol amounts higher than the theoretical amount was used to favor the formation of fatty acid esters [34,35]. The effect of methanol amount on FAME content in the in situ methanolysis of wet C. vulgaris biomass is shown in Fig. 4 .

Fig. 4 shows that as the amount of methanol $(\mathrm{mL})$ per gram of wet microalgae was raised from 2 to 4 , the FAME content in the product increased from $79.45 \%$ to $89.71 \%$. Further increase in methanol amount (6 or $8 \mathrm{~mL}$ ) caused a slight decrease in FAME content. It has been suggested that the presence of excess methanol in transesterification process is essential since it is responsible for breaking the glycerin-fatty acid linkages [36]. A study on biodiesel preparation from Chlorella protothecoides showed that excess methanol in large quantities reduced the amount of products and slowed down the separation of glycerol and FAME [6]. The conversion of crude microalgal oil to biodiesel increased with increasing methanol to oil ratio. This reached a maximum and started to decrease when methanol to oil ratio was further increased [8]. A similar trend was observed in this study (Fig. 4).

According to Yin et al. [30], the advantage of using excess $\mathrm{MeOH}$ is that the reaction can be carried out in one phase because oil becomes soluble in subcritical methanol. Both yield of FAME and reaction rate are enhanced due to homogeneous mixture of reactants as well as higher concentration of methanol which favors FAME formation. We found that a wet microalgae biomass to methanol ratio of $1: 4(\mathrm{w} / \mathrm{w})$ was necessary to achieve maximum FAME yield because the presence of excess methanol is conducive to extracting microalgae oil and transforming the oil into FAMEs.

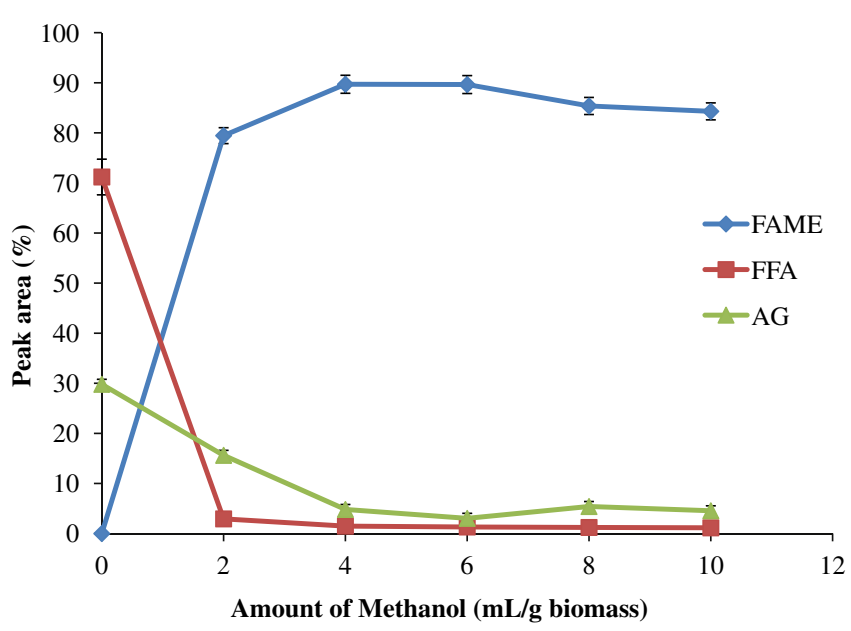

Fig. 4. Effect of methanol amount on product composition. Reaction conditions: $5 \mathrm{~g}$ wet microalgae ( $80 \%$ moisture content), $175^{\circ} \mathrm{C}$ and 22 bar, reaction time $4 \mathrm{~h}$.

The water amount was fixed at $4 \mathrm{~g}$ water per g dry microalgae to simulate the moisture content of wet algae after harvesting. In our previous study on producing FAMEs from soybean oil under subcritical condition, it was found that water amount did have significant effect on the yield of FAMEs [40].

\subsection{Composition of FAMEs}

FAME profile of the product was analyzed by using gas chromatography and the result is shown in Table 1.

Palmitoleic acid methyl ester (C16:1) is the most abundant FAME present in the biodiesel produced from the in situ methanolysis of $C$. vulgaris under subcritical condition. Other FAMEs present in substantial amounts $(\sim 15 \%)$ are palmitic acid methyl ester (C16:0), linolenic acid methyl ester (C18:3n3), and linoleic acid methyl ester (C18:2n6c). The fatty acids composition of lipids from C. vulgaris was studied by Petkov and Garcia [37] and their results are similar to ours. Small quantities of methyl esters from fatty acids with less than 15 carbons and more than 19 carbons were also observed in this study, and was confirmed by a previous study [38]. The presence of substantial amounts of linolenic acid methyl ester (15.19\%), and linoleic acid methyl ester (13.84\%) will have negative effect on the oxidative stability of the biodiesel produced. Modifying fatty acid profile of $C$. vulgaris through genetic

Table 1

Composition of FAMEs produced from wet biomass of Chlorella vulgaris at $175^{\circ} \mathrm{C}$ and 22 bar. Each value is the average of two independent experiments.

\begin{tabular}{lc}
\hline Type of FAME & $\begin{array}{c}\text { Amount } \\
\text { (peak area (\%)) }\end{array}$ \\
\hline Capric acid methyl ester (C10:0) & 0.85 \\
Lauric acid methyl ester (C12:0) & 3.32 \\
Tridecanoic acid methyl ester (C13:0) & 1.41 \\
Myristic acid methyl ester (C14:0) & 6.5 \\
cis-10-Pentadecenoic acid methyl ester (C15:1) & 3.17 \\
Palmitic acid methyl ester (C16:0) & 15.66 \\
Palmitoleic acid methyl ester (C16:1) & 27.73 \\
cis-10-Heptadecenoic acid methyl ester (C17:1) & 3.86 \\
Stearic acid methyl ester (C18:0) & 0.21 \\
Elaidic acid methyl ester (C18:1n9t) & 6.08 \\
Oleic acid methyl ester (C18:1n9c) & 1.32 \\
Linoleic acid methyl ester (C18:2n6c) & 13.84 \\
cis-11-Eicosenoic acid methyl ester (C20:1n9) & 0.33 \\
Linolenic acid methyl ester (C18:3n3) & 15.19 \\
cis-5,8,11,14,17-Eicosapentaenoic acid methyl ester (C20:5n3) & 0.32 \\
Nervonic acid methyl ester (C24:1n9) & 0.21 \\
\hline
\end{tabular}


manipulation and/or optimizing of culturing conditions on this species is required if it is to be considered as a potential candidate as feedstock for biodiesel production.

\section{Conclusion}

A catalyst free method to produce biodiesel directly from wet biomass of $C$. vulgaris under subcritical condition was studied. Stirring has positive effect on the reaction by shortening reaction time required to achieve high conversion. The maximum biodiesel yield from C. vulgaris using this method was $0.29 \mathrm{~g} / \mathrm{g}$ dry biomass. This was obtained under the following conditions: $5 \mathrm{~g}$ wet biomass ( $80 \%$ moisture content), $20 \mathrm{~mL}$ methanol, $175^{\circ} \mathrm{C}$, with stirring for $4 \mathrm{~h}$. This compares favorably with the theoretically yield of $0.20 \mathrm{~g}$ FAME/g dry biomass which can be obtained by firstly extracting all neutral lipids from dry biomass of $C$. vulgaris and then transform all neutral lipids into FAMEs.

\section{Acknowledgements}

This work was supported by National Science Council of Taiwan through the grant NSC100-2623-E-011 -001-ET. We are also thankful to Professor Jo-Shu Chang, National Chung Kung University, for his generous gift of the Chlorella vulgaris biomass.

\section{References}

[1] Q. Hu, M. Sommerfeld, E. Jarvis, M. Ghirardi, M. Posewitz, M. Seibert, A Darzins, Microalgal triacylglycerols as feedstocks for biofuel production: perspectives and advances, Plant J. 54 (2008) 621-639.

[2] C. Yusuf, Biodiesel from microalgae, Biotechnol. Adv. 25 (2007) 294-306.

[3] M. Huntley, D. Redalje, $\mathrm{CO}_{2}$ mitigation and renewable oil from photosynthetic microbes: a new appraisal, Mitig. Adapt. Strat. Global Change 12 (2007) 573608.

[4] R. Halim, M.K. Danquah, P.A. Webley, Extraction of oil from microalgae for biodiesel production: a review, Biotech. Adv. (2012), http://dx.doi.org/ 10.1016/j.biotechadv.2012.01.001.

[5] J.Y. Lee, C. Yoo, S.Y. Jun, C.Y. Ahn, H.M. Oh, Comparison of several methods for effective lipid extraction from microalgae, Bioresour. Technol. 101 (2010) S75S77.

[6] X. Miao, Q. Wu, Biodiesel production from heterotrophic microalgal oil, Bioresour. Technol. 97 (2006) 841-846.

[7] N. Nagle, P. Lemke, Production of methyl ester fuel from microalgae, Appl Biochem. Biotechnol. 24-25 (1990) 355-361.

[8] D.T. Tran, K.L. Yeh, C.L. Chen, J.S. Chang, Enzymatic transesterification of microalgal oil from Chlorella vulgaris ESP-31 for biodiesel synthesis using immobilized Burkholderia lipase, Bioresour. Technol. (2012), http://dx.doi.org/ 10.1016/j.biortech.2011.12.145

[9] F. Pernet, R. Tremblay, Effect of ultrasonication and grinding on the determination of lipid class content of microalgae harvested on filters, Lipids 38 (2003) 1191-1195.

[10] K.H. Wiltshire, M. Boersma, A. Möller, H. Buhtz, Extraction of pigments and fatty acids from the green alga Scenedesmus obliquus (Chlorophyceae), Aquat. Ecol. 34 (2000) 119-126.

[11] S. Al-Zuhair, Production of biodiesel: possibilities and challenges, Biofuels Bioprod Biorefin 1 (2007) 57-66.

[12] R.B. Levine, T. Pinnarat, P.E. Savage, Biodiesel production from wet algal biomass through in situ lipid hydrolysis and supercritical transesterification, Energy Fuels 24 (2010) 5235-5243.
[13] E.A. Ehimen, Z.F. Sun, C.G. Carrington, Variables affecting the in situ transesterification of microalgae lipids, Fuel 89 (2010) 677-684.

[14] S.B. Velasquez-Orta, J.G.M. Lee, A. Harvey, Alkaline in situ transesterification of Chlorella vulgaris, Fuel 94 (2012) 544-550.

[15] R. Xu, Y. Mi, Simplifying the process of microalgal biodiesel production through in situ transesterification technology, J. Am. Oil Chem. Soc. 88 (2011) 91-99.

[16] B.D. Wahlen, R.M. Willis, L.C. Seefeldt, Biodiesel production by simultaneous extraction and conversion of total lipids from microalgae, cyanobacteria, and wild mixed-cultures, Bioresour. Technol. 102 (2011) 2724-2730.

[17] D. Ayhan, Biodiesel from waste cooking oil via base-catalytic and supercritica methanol transesterification, Energy Convers. Manage. 50 (2009) 923-927.

[18] H. He, T. Wang, S. Zhu, Continuous production of biodiesel fuel from vegetable oil using supercritical methanol process, Fuel 86 (2007) 442-447.

[19] V.F. Marulanda, G. Anitescu, L.L. Tavlarides, Investigations on supercritical transesterification of chicken fat for biodiesel production from low-cost lipid feedstocks, J. Supercrit. Fluids 54 (2010) 53-60.

[20] J.Z. Yin, M. Xiao, J.-B. Song, Biodiesel from soybean oil in supercritical methanol with co-solvent, Energy Convers. Manage. 49 (2008) 908-912.

[21] D. Kusdiana, S. Saka, Effects of water on biodiesel fuel production by supercritical methanol treatment, Bioresour. Technol. 91 (2004) 289-295.

[22] D. Ayhan, Biodiesel production via non-catalytic SCF method and biodiesel fuel characteristics, Energy Convers. Manage. 47 (2006) 2271-2282.

[23] E.S. Song, J.W. Lim, H.S. Lee, Y.W. Lee, Transesterification of RBD palm oil using supercritical methanol, J. Supercrit. Fluids 44 (2008) 356-363.

[24] R.L. Holliday, J.W. King, G.R. List, Hydrolysis of vegetable oils in sub- and supercritical water, Ind. Eng. Chem. Res. 36 (1997) 932-935.

[25] P. Khuwijitjaru, T. Fujii, S. Adachi, Y. Kimura, R. Matsuno, Kinetics on the hydrolysis of fatty acid esters in subcritical water, Chem. Eng. J. 99 (2004) 1-4

[26] A.T. Quitain, M. Faisal, K. Kang, H. Daimon, K. Fujie, Low-molecular-weigh carboxylic acids produced from hydrothermal treatment of organic wastes, J. Hazard. Mater. 93 (2002) 209-220.

[27] Y.A. Tsigie, L.H. Huynh, I.N. Ahmed, Y.-H. Ju, Maximizing biodiesel production from Yarrowia lipolytica Po1g biomass using subcritical water pretreatment, Bioresour. Technol. 111 (2012) 201-207.

[28] L.H. Huynh, N.S. Kasim, Y.H. Ju, Extraction and analysis of neutral lipids from activated sludge with and without sub-critical water pre-treatment, Bioresour. Technol. 101 (2010) 8891-8896.

[29] T. Rogalinski, S. Herrmann, G. Brunner, Production of amino acids from bovine serum albumin by continuous sub-critical water hydrolysis, J. Supercrit. Fluids 36 (2005) 49-58.

[30] J.Z. Yin, Z. Ma, D.-P. Hu, Z.L. Xiu, T.H. Wang, Biodiesel production from subcritical methanol transesterification of soybean oil with sodium silicate, Energy Fuels 24 (2010) 3179-3182.

[31] K.L. Yeh, J.S. Chang, W.M. Chen, Effect of light supply and carbon source on cell growth and cellular composition of a newly isolated microalga Chlorella vulgaris ESP-31, Eng. Life Sci. 10 (2010) 201-208.

[32] Y.A. Tsigie, C.Y. Wang, C.-T. Truong, Y.H. Ju, Lipid production from Yarrowia lipolytica Po1g grown in sugarcane bagasse hydrolysate, Bioresour. Technol. 102 (2011) 9216-9222.

[33] L. Lascaray, Mechanism of fat splitting, Ind. Eng. Chem. 41 (1949) 786-790.

[34] K. de Boer, P.A. Bahri, Supercritical methanol for fatty acid methyl ester production: a review, Biomass Bioenergy 35 (2011) 983-991.

[35] D. Kusdiana, S. Saka, Kinetics of transesterification in rapeseed oil to biodiesel fuel as treated in supercritical methanol, Fuel 80 (2001) 693-698.

[36] M.I. Al-Widyan, A.O. Al-Shyoukh, Experimental evaluation of the transesterification of waste palm oil into biodiesel, Bioresour. Technol. 85 (2002) 253-256.

[37] G. Petkov, G. Garcia, Which are fatty acids of the green alga Chlorella?, Biochem Syst. Ecol. 35 (2007) 281-285.

[38] T. Heredia-Arroyo, W. Wei, R. Ruan, B. Hu, Mixotrophic cultivation of Chlorella vulgaris and its potential application for the oil accumulation from non-sugar materials, Biomass Bioenergy 35 (2011) 2245-2253.

[39] F. Ma, L.D. Clements, M.A. Hanna, The effect of mixing on transesterification of beef tallow, Bioresour. Technol. 69 (1999) 289-293.

[40] Y.H. Ju, L.H. Huynh, Y.A. Tsigie, Q.P. Ho, Synthesis of Biodiesel in Subcritical Water and Methanol, Fuel, http://doi:10.1016/j.fuel.2012.05.061. 